\title{
Registro de sueños. Atisbos a la conciencia onírica desde las ciencias, las artes y la filosofía
}

\author{
Alejandro Sandoval Maza
}

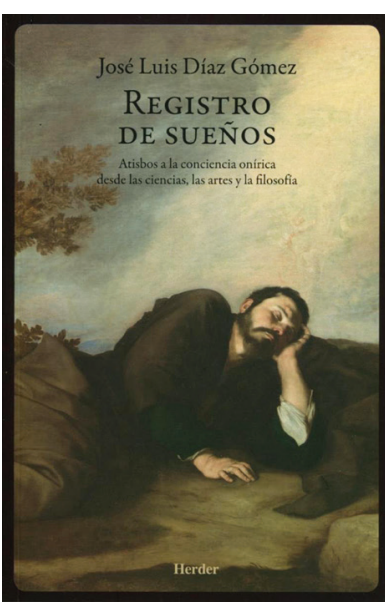

Díaz Gómez, J. L. (2018). Registro de sueños. Atisbos a la conciencia onírica desde las ciencias, las artes y la filosofía. Ciudad de México: Herder.

DOI: $10.17711 /$ SM.0185-3325.2018.020

\section{(c) (i) (5)}

Se trata de un libro muy interesante que, de una manera amena y erudita, entrelaza múltiples niveles de aproximación a un fenómeno tan humano como la ensoñación. Por supuesto, no sólo los humanos ensoñamos, pero no tenemos manera de interrogar a otras especies acerca del mundo que habitan o sobre cómo es el mundo de sus sueños. En el caso de los humanos, se trata ciertamente de un mundo rico en contenidos y polimorfo en su arquitectura espacio-temporal. Sin embargo, al conocer el tipo de información proveniente de los aparatos perceptuales, la forma en que ésta se integra y se maneja con procesos neurobiológicos más o menos conocidos, así como su expresión ejecutada mediante conductas específicas, se puede intentar hacer modelos que representen el campo de la conciencia en diferentes especies incluyendo al humano. El ensueño es una forma de conciencia, pero con restricciones que van desde la disminución en el funcionamiento de algunas áreas cerebrales, cambios en la arquitectura tanto funcional como neuroquímica, hasta modificaciones en la relación del organismo con el ambiente externo.

Para los psiquiatras que nos dedicamos a la psicoterapia y que estamos interesados en las neurociencias y en las artes, éste es un libro que nos permite reflexionar acerca del complejo camino que nos conduce a comprender el mundo interno de nuestros pacientes. Me refiero a la noción de 'mundo' en el sentido que le dio Jakob von Uexkull, ${ }^{1}$ porque es precisamente en la conciencia expresada en los ensueños donde podemos apreciar un modelo generativo del mundo bajo condiciones específicas. Es ahí, en la experiencia fenoménica del ensueño, donde apreciamos al Yo del sujeto percibiendo, sintiendo, actuando y literalmente viviendo situaciones que, vistas desde la vigilia, pueden parecer absurdas, ridículas o escalofriantes.

Los sueños pueden constituir la "vía regia" para acceder a la conciencia del soñante y nos permiten entender cómo ésta influye en la conciencia de la vigilia. Este concepto es complejo y en el libro se habla explícitamente de la conciencia onírica, es decir, de la experiencia del soñar, así como su recuperación, narración, interpretación y representación, la cual es un campo que delimita y separa un estado interno del sujeto en el aquí y ahora (del sueño) y, como campo, nos plantea un entrelazado complejo de contenidos de la memoria con un fuerte componente emocional que en la experiencia subjetiva parece tener un sentido casi coherente. Y, sin embargo, en la vigilia podemos diferenciar claramente la conciencia diurna de la nocturna. Me parece que el autor se afilia a la idea de Domhoff, quien señala que existe una continuidad en la conciencia desde el sueño al estado de vigilia. En este sentido, es útil recordar la definición de Ey (1978) de la conciencia,"la organización de la experiencia sensible actual que integra: la presencia en el mundo, la representación del orden objetivo y subjetivo y la construcción del presente", porque entonces las modificaciones que tendríamos que hacerle a esta definición durante el soñar son más bien de forma que de contenido, pues aunque están cancelados ciertos canales perceptuales, sí hay "percepciones" durante la fase REM como lo menciona el

Umwelt: Medio ambiente percibido de manera subjetiva por el organismo.

2 Para usar una expresión de Freud y una idea del Dr. Salín. 
Dr. Díaz y muchos otros autores. Lo que resta es la función estabilizadora de la información derivada de los órganos sensoriales, pero se cuenta con la información de las áreas de asociación.

La idea de la organización en las palabras de Ey se ha seguido utilizando por los neurocientíficos para explicar estados de la mente, de modo que se ha planteado que las experiencias del ensueño durante la fase MOR son inherentes a las propiedades auto-organizadoras del cerebro (Kahn, Krippner, \& Combs, 2000). Desde un punto de vista más actual, se considera que la conciencia tanto onírica como en la vigilia se puede equiparar a la actividad inferencial (Hobson, Hong, \& Friston, 2014), es decir, el cerebro mismo es un órgano que sirve para hacer inferencias que predicen el estado del mundo y del sujeto a través de la información disponible en un momento dado. Serían una realidad virtual que generan conductas apropiadas en el mundo cambiante y profundamente demandante de la vigilia.

En los diferentes capítulos, el Dr. Díaz va articulando el abordaje de los ensueños partiendo de los conocimientos derivados de las neurociencias y los dispositivos con los que se cuenta para cuantificar y evaluar hipótesis. Tal es el caso del electroencefalograma, magnetoencefalograma, resonancia magnética funcional, tomografía por emisión de positrones, etc. Una hipótesis que me parece muy interesante es la de plantear una red neural que soporta y que genera la experiencia consciente durante el dormir a la cual le llama el "circuito de Morfeo". Las redes neurales son una herramienta muy útil tanto práctica como teóricamente para abordar múltiples fenómenos dentro de las neurociencias, ya que permiten hacer planteamientos en diferentes niveles de aproximación acerca del procesamiento de la información en circuitos o redes que se han segregado al servicio de funciones específicas pero que, a su vez, se integran para soportar funciones más elaboradas y en última instancia será el balance entre segregación e integración en los circuitos neuronales lo que constituirá el desempeño normal o patológico del cerebro.

Se han caracterizado múltiples redes neuronales de largo alcance, es decir, que conectan varias áreas cerebrales, como es el caso de la red de la atención; la central ejecutiva, la red basal, etc. Lo interesante de estas redes es su dinamismo, es decir, para unas tareas se activan al mismo tiempo que para otras se inactivan, lo que se conoce como anticorrelación. Una red muy interesante y pertinente para el estudio de los ensueños es la denominada red basal o de modo por default (DMN, por sus siglas en inglés) (Raichle, 2010); ésta es la red que se encuentra activa en la ensoñación diurna, durante la creación de fantasías, en la simulación mental y en los sueños, entre otras actividades. Este conocimiento ha resaltado la importancia de la actividad intrínseca cerebral y ha permitido aproximarnos al campo de la conectividad cerebral tanto en estado de reposo como cuando se realizan tareas específicas. Se cuenta con un amplio estado de la cuestión sobre las redes neurales en general y el DMN en particular. Seguramente en los siguientes años va a ser una obligación para los psiquiatras el conocer ampliamente tanto la estructura anatómica como funcional de las mismas y la consideración del campo de la conectómica (Fornito \& Bullmore, 2015) en el análisis de los pacientes.

Echando mano del análisis de los sueños en conjunto con todas las herramientas disponibles, en algún momento se podrá evaluar la marca neuro-psico-biológica del Yo del sujeto como una red neural específica que se manifiesta en los diferentes contextos, en los cuales es necesario una entidad psíquica que organice la información, ya sea en la vigilia como durante el sueño. Es decir, mediante un análisis abarcativo que incluya datos objetivos y subjetivos, se podría explorar al Yo como un elemento esencial en la constitución de la personalidad, la cual se define como el "Yo en tanto dueño de su carácter, autor de su personaje, artesano de su mundo y sujeto de autoconocimiento" (Ey, 1978). Todos estos elementos los apreciamos en las narraciones de los ensueños y los vemos plásticamente metamorfoseándose en un imaginario personal.

Como apunta muy bien el autor, el ensueño es en sí mismo el resultado de un trabajo psíquico, pues representa el resultado final de un proceso que comienza en el cerebro y termina en la representación verbal que puede abarcar desde el lenguaje individual hasta las formas socioculturales. Por ser un proceso recursivo de lo individual a lo colectivo adquiere formas que se pueden llegar a apreciar estéticamente. Entonces los ensueños son una herramienta poderosa para entender al hombre y su circunstancia. Por ello, uno de los aspectos fascinantes del libro es la propuesta de crear una especialidad que se aboque al estudio del soñar en todas sus dimensiones, la Onirología. Me encantaría que fuera una subespecialidad de la psiquiatría porque incluye las ciencias, las artes y las humanidades, y estoy seguro de que muchos colegas se sumarían a esta empresa, sin embargo, hay mucho camino por recorrer, muchos obstáculos que superar y especialmente, plantear de la mejor manera posible cuál sería la meta de dicho esfuerzo. El Dr. Díaz nos lleva al Sinaí y señala un decálogo de proposiciones que es su manifiesto onirológico, el cual nos puede servir de punto de partida.

Los diez planteamientos me parecen pertinentes y puedo pensar que anuncian futuros libros, porque cada uno nos puede llevar por caminos muy ricos y extensos; sin embargo, lo más interesante será el ejercicio de integración necesario para poder realmente comprender la dinámica de la mente durante el ensueño. Sólo voy a mencionar dos por razones de extensión. En su primera propuesta, que es la condensación de los primeros capítulos del libro, nos señala que el ensueño tiene una secuencia fragmentada para ser vista desde múltiples ángulos, es decir, para su comprensión se requiere un ejercicio transdisciplinario, en donde todos los puntos de vista tengan un rol para la integración teórica, 
metodológica e incluso hermenéutica. Una teoría abarcativa, sustentada en estudios experimentales y con bases neurofisiológicas, puede servir de organizador común a todos los discursos. De ahí que el segundo planteamiento nos remite al cerebro desde donde surge la conciencia del ensueño como el resultado del funcionamiento de una hipotética red neural oniromórfica capaz de "engendrar una trama narrativa mediante el enlace de áreas y procesos sensoriales, afectivos, semánticos y volitivos del sistema mente-cerebro". Las dicotomías mente/cerebro, objetivo/subjetivo, etc., confluyen en una experiencia personal como el ensueño y esto da sustento a posturas filosóficas de la mente como el "monismo de aspecto dual".

Como señalé en líneas anteriores, al plantear una red neural estaríamos adhiriéndonos a la consideración de los dos principios básicos del cerebro, a saber, la integración funcional y la especialización funcional (Friston, 2002) y de ahí a una idea más general que se denomina "el cerebro Bayesiano" (Friston, 2012) que nos señala que el cerebro trata de inferir las causas de sus sensaciones basado en un modelo generativo del mundo. Aunque en el libro no se habla explícitamente de esta teoría, muchos autores de la extensa bibliografía del libro sí se han afiliado de una o de otra manera a esta postura teórica que está de moda en el mundo de las neurociencias. Autores como Metzinger, Llewellyn, Windt, Hobson, Solms, Revonsuo, Domhoff, etc., nos están brindando una explicación parsimoniosa tanto de la experiencia onírica subjetiva como de la importancia de los ensueños para la optimización de la información contenida en las imágenes, es decir, para maximizar la eficiencia del sistema y generar evidencias, así como minimizar la redundancia o, dicho de otra manera, "constreñir la complejidad".

El libro tiene muchas ideas interesantes, pero una especialmente destacable sugiere que "el ensueño puede ser tomado como una metáfora valiosa y fructífera para reflexionar sobre uno mismo". Parece simple, pero en realidad es muy compleja si tratamos de seguir la secuencia que anuncia, por ejemplo, una imagen acarrea información de una forma de representación a otra siguiendo patrones probabilísticos que para estabilizarse en la siguiente forma repre- sentacional puede caer en un punto dentro de un continuum, entre el orden y el caos, y ahí se fija un "sí mismo". Las formas que elige la mente para representar algo son, hasta cierto punto, inestables (criticalidad) pero expresan metaestabilidad (integración de múltiples elementos funcionales que cooperan y se coordinan para generar la conciencia). No ahondaré en esto, pero basta decir que el libro trabaja varias formas de representación de los ensueños. Estas formas nos permitirían hacer ingeniería reversa para entender la mecánica de la articulación de los ensueños. Así, el Dr. Díaz utiliza los sueños en la literatura fantástica, en obras pictóricas que explícitamente pintan sueños y, más hacia nuestro mundo actual, nos adentra en el cine como arte onírico. Los ensueños fílmicos los plantea como un modelo interesante para analizar el modelaje de la mente en la creación de los ensueños, porque ahí se aprecian con mucha claridad los fenómenos de la alteración del espacio-tiempo, así como las metamorfosis y oscilaciones del Yo onírico.

Para concluir, el libro Registro de sueños es un portal para adentrarnos en el campo de los ensueños desde un análisis serio, que asume sin lugar a dudas que el fenómeno onírico tiene una función importante dentro de las actividades cerebrales y consecuencias vitales para la homeostasis neurobiológica, la adaptación al mundo que nos rodea, la comprensión del mundo interno que habitamos y en última instancia, la sabiduría personal.

\section{REFERENCIAS}

Ey, H. B. P. (1978). Tratado de Psiquiatría. Ciudad de México: Masson.

Fornito, A. \& Bullmore, E. T. (2015). Connectomics: A new paradigm for understanding brain disease. European Neuropsychopharmacology, 25(5), 733-748.

Friston, K. (2002). Beyod phrenology: what can neuroimaging tell us about distributed circuitry?. Annual Reviews Neuroscience, 25(1), 221-250.

Friston, K. (2012). The history of the future of the Bayesian brain. Neuro Image, 62(2), 1230-1233

Hobson, J., Hong, C. C. H., \& Friston, K. J. (2014). Virtual reality and consciousness inference in dreaming. Frontiers in Psychology, 5, 1133.

Kahn, D., Krippner, S., \& Combs, A. (2000). Dreaming and the Self-organizing brain. Journal of Consciousness Studies, 7(7), 4-11.

Raichle, M. (2010). Two views of brain function. Trends in Cognitive Sciences, 14(4), 180-190. 